The international nature, impartiality and neutrality of the Red Cross stand it in good stead, enabling it to respond quickly to needs in many different situations.

Despite its harnessing of modern technology, the Red Cross intends to remain a relief agency with a human dimension. It knows its most important asset is its human resources-millions of men, women and young people who channel their urge to help through their National Society. In an age when the individual feels he counts for less, Red Cross is saying people matter-and holding out a lifeline.

\title{
SYMPOSIUM ON THE DEVELOPMENT OF THE RED CROSS IN AFRICA
}

A symposium on the development of the Red Cross and Red Crescent in Africa, organized by the League of Red Cross Societies, took place at Montreux, Switzerland, from 24 February to 8 March. Representatives of 34 African and of a dozen other National Societies took part. Dr Eric Martin, President of the ICRC, addressed the opening session, emphasizing the vital role facing the Red Cross in a world still dominated too often by instability and violence. On the occasion of ICRC Day, 7 March, the ICRC delegate-general for Africa summarized the main lines of the institution's activities in Africa, especially in the field of assistance to prisoners.

Food aid supplied by the ICRC and distributed by the National Societies, and the diffusion of humanitarian law and the principles of the Red Cross were two of the subjects of lectures and animated discussions.

The symposium was important for a number of reasons and we shall mention it again next month. 